\title{
Response to Inhaled Nitric Oxide and Clinical Outcome in Very Low Birth Weight Infants with Early Pulmonary Hypertension
}

Jae Young Cho, $\mathrm{MD}^{1}$, Byong Sop Lee, $\mathrm{MD}, \mathrm{PhD}^{2}$, Moon Yeon $\mathrm{Oh}, \mathrm{MD}^{2}$, Teahyen Cha, $\mathrm{MD}^{2}$, Jiyoon Jeong, $\mathrm{MD}^{2}$, Euiseok Jung, $\mathrm{MD}^{2}$, Ai-Rhan Kim, MD, $\mathrm{PhD}^{2}$, and Ki-Soo Kim, MD, PhD ${ }^{2}$

${ }^{1}$ Department of Pediatrics, Gyeongsang National University College of Medicine, Jinju, Korea

${ }^{2}$ Department of Pediatrics, Asan Medical Center, University of Ulsan College of Medicine, Seoul, Korea

\section{ABSTRACT}

Purpose: To determine the efficacy of inhaled nitric oxide (iNO) in very low birth weight (VLBW) infants with early pulmonary hypertension (PH).

Methods: We reviewed the medical records of 22 preterm infants who were born $<30$ weeks of gestational age with birth weight $<1,500 \mathrm{~g}$, diagnosed with early $\mathrm{PH}$, and treated with iNO within the first 72 hours after birth. Responders were defined by a reduction in $\mathrm{FiO}_{2}>20 \%$ and/or oxygenation index $(\mathrm{OI})>20 \%$ from the baseline values at 1 hour after beginning iNO therapy. Cardiorespiratory support indices including OI, oxygen saturation index, and vasoactive-inotropic score (VIS) were serially obtained for 96 hours following iNO therapy.

Results: The mean gestational age of the patients was $26.1 \pm 2.0$ weeks and the mean birth weight was $842 \pm 298 \mathrm{~g}$. The mean OI at the start of iNO was $63.8 \pm 61.0$. Improvement in oxygenation indicated by prompt decrease in $\mathrm{FiO}_{2}$ and $\mathrm{OI}$ from the baseline values were observed 1 hour after beginning iNO therapy and lasted up to 96 hours. After iNO therapy, VIS increased until 24 hours and decreased thereafter. At 1 hour after iNO, 16 patients (73\%) were classified as responders and six (27\%) as nonresponders. Compared with nonresponders, responders did not demonstrate the beneficial effect of iNO in terms of short-term survival and neonatal complications. The 1-year mortality rate did not differ between responders (56\%) and nonresponders (67\%).

Conclusion: Although iNO treatment immediately improved oxygenation in most VLBW infants with early severe PH, the long-term mortality rate was high. A largescale study is needed to determine whether the initial response to iNO can predict patients' survival.

Key Words: Infant, very low birth weight; Hypertension, pulmonary; Nitric oxide
Received: 19 May 2020

Revised: 5 June 2020

Accepted: 9 June 2020

Correspondence to: Byong Sop Lee, $\mathrm{MD}, \mathrm{PhD}$

Department of Pediatrics, Asan Medical Center, University of Ulsan College of Medicine, 88 Olympic-ro 43-gil, Songpa-gu, Seoul 05505, Korea

Tel: +82-2-3010-3372

Fax: +82-2-3010-7302

E-mail:mdleebs@amc.seoul.kr

Copyright(c)

By Korean Society of Neonatology.

All right reserved.

This is an Open-Access article distributed under the terms of the Creative Commons Attribution Non-Commercial License (http:// creativecommons.org/licenses/by-nc/4.0), which permits unrestricted non-commercial use, distribution, and reproduction in any medium, provided the original work is pro perly cited. 
서론

태아 순환은 출생 후 산소 노출로 인한 폐혈관저항 감소와 태반 탈락 후 전신 혈관저항 증가의 과정을 거치면서 신생아 순환으로 이 행된다. 출생 직후 발생하는 조기 폐동맥고혈압(pulmonary hypertension)은 여러 산전 요인과 분만 과정의 저산소성 손상 등으로 인 해 정상적인 태아 순환에서 신생아 순환으로의 이행 과정에 문제 가 생기고 이로 인한 순환 부전에 따른 사망까지 이를 수 있는 심 각한 질환이다 ${ }^{1}$. 폐동맥고혈압 치료는 원인 교정과 더불어 환기 및 순환 유지, 적절한 산소화 등 보존적 치료가 우선적으로 고려되며 이와 같은 보존적 치료에도 불구하고 호흡곤란과 혈역학적 불안정 성이 해결되지 못하는 중증 폐동맥고혈압으로 생각되는 경우 선택 적 폐동맥확장제인 흡입일산화질소(inhaled nitric oxide, $\mathrm{iNO}$ )가 가 장 핵심적인 치료이다. iNO는 메타분석에서 재태주령 34 주 이상 신생아 지속성 폐동맥고혈압(persistent pulmonary hypertension of newborn, PPHN)의 생존율을 높이고 체외막산소공급(extracorporeal membrane oxygenation)의 필요성을 감소시키는 것으로 알 려져 있달. 미숙아도 여러 주산기 요인으로 인해 생후 초기 폐동맥 고혈압이 발생할 수 있으며 만삭아보다 사망률이 높다3,4). 출생체 중 $1,500 \mathrm{~g}$ 미만, 재태주령 28 주 미만 미숙아 연구에서 폐동맥고혈 압이 있는 경우 대조군에 비하여 3.5배 높은 사망률을 보였고 재태 주령이 낮을수록 폐동맥고혈압의 발생 빈도가 높았다5). 미숙아에서 발생하는 조기 폐동맥고혈압의 원인은 다양하다. 장기간의 조기양 막파열로 인한 폐형성저하가 가장 중요한 원인으로 알려져 있으며 이외에도 융모양막염(chorioamnionitis), 산모의 선택 세로토닌 재 흡수억제제(selective serotonin reabsorption inhibitor) 복용력, 쌍 태아간 수혈증후군 등도 위험인자이다 ${ }^{6-8)}$. 그러나 미숙아에서 발생 한 조기 폐동맥고혈압에서는 아직 대증적 치료가 주된 치료이며 중 증 조기 폐동맥고혈압에 대한 구제 치료(rescue therapy)로서 경험 적으로 $\mathrm{iNO}$ 치료가 시도되고 있으나 이에 대한 효과 및 안전성에 대 한 근거가 부족하다,10). 최근 메타분석에서 저산소성 호흡부전이 동 반된 미숙아에서 생후 초기 구제 치료로서 iNO를 사용했을 경우 비 록 뇌실내출혈, 폐출혈 등의 급성기 부작용의 위험성을 증가시키지 는 않지만, 생존율 감소 효과는 뚜렷하지 않았고 기관지폐이형성증 (bronchopulmonary dysplasia, BPD) 등의 후기 합병증도 감소시키 지 못하는 것으로 발표된바 있다 ${ }^{11)}$.

현재까지 다양한 병인을 가진 미숙아 저산소성 호흡부전에서 $\mathrm{iNO}$ 사용에 대한 근거가 불충분함에도 불구하고 장기간의 조기 양 막 파수에 따른 폐형성 저하 등 일부 미숙아 질환에서 기존의 보존 적 치료와 병용하거나 또는 우선적으로 사용된 iNO 흡입 치료가 효 과적이라는 연구들이 발표되고 있다 ${ }^{12-14)}$. 미숙아 조기 폐동맥고혈 압에서 적극적인 $\mathrm{iNO}$ 치료의 근거로 재태연령이 어릴수록 흡입산 소분율 $\left(\mathrm{FiO}_{2}\right) 50 \%$ 이상의 산소분압에 대한 폐혈관저항의 감소 효과
가 크지 않고, 오히려 동맥혈 산소분압의 증가가 $\mathrm{iNO}$ 의 효과를 떨어 뜨릴 가능성이 제시된다 ${ }^{15}$. 그러나 국내에서는 아직 34 주 미만 미숙 아에서 적극적인 $\mathrm{iNO}$ 의 사용은 보험 기준 등 여러 요인에 의하여 제 한적이며, 특히 생후 초기 발생한 중증 폐동맥고혈압에 대한 $\mathrm{iNO}$ 의 효과에 대한 연구는 부족하다. 미숙아에서의 iNO 사용에 대한 몇몇 국내 보고가 있으나 출생 초기에 확인된 중증 폐동맥고혈압에 국한 된 환자군에서 $\mathrm{iNO}$ 의 효과를 확인한 연구는 없다 ${ }^{13,16)}$.

본 연구의 목적은 중증 조기 폐동맥고혈압으로 진단된 재태주령 30 주 미만의 극소 저체중출생아에서 iNO 투여 치료의 반응과 이에 따른 임상 경과를 확인하는 것이다.

\section{대상 및 방법}

2009년 1월부터 2018년 12월까지 서울아산병원에서 출생하여 신 생아중환자실에 입원한 재태주령 30 주 미만이면서 출생체중 1,500 $\mathrm{g}$ 미만인 환자 중 생후 72 시간 이내에 침습적 인공환기요법과 함께 $\mathrm{iNO}$ 흡입 치료를 받은 환자를 대상으로 후향적으로 의무기록을 분 석하였다. 폐형성저하 이외의 주요 선천성 기형 및 염색체 이상이 확인된 경우, 태아수종이 동반된 경우, $\mathrm{iNO}$ 적용 한 시간 이내 사망 하여 반응을 관찰하지 못하는 경우는 연구 대상에서 제외되었다. 조 기 폐동맥고혈압은 폐표면활성제의 투약과 침습적 인공환기치료에 도 불구하고 생후 72 시간 이내에 폐동맥고혈압이 확인된 경우로 정 의하였다 ${ }^{17}$. 폐동맥고혈압의 정의는 아래와 같은 임상적 기준 또는 심초음파 상의 기준을 만족하는 경우로 하였다. 임상적 기준은 $\mathrm{FiO}_{2}$ $>0.6$ 과 함께 동맥관 전/후 산소포화도의 차이 $>10 \%$ 또는 동맥혈 가 스검사로 계산된 산소화지수(oxygenation index, OI) $>15$ 이상이었 다. 조기 폐동맥고혈압에 대한 심초음파 기준은 생후 3 일 이내에 시 행한 검사에서 (1) 추정되는 우심실의 수축기 혈압이 전신 수축기 혈압의 $1 / 2$ 이상, (2) 심실 중격의 범수축기 D shape 또는 bowing 소 견, (3) 난원공(이차성 심방중격결손)이나 동맥관을 통한 우좌 또는 양측 단락의 관찰 중 하나 이상의 소견이 있는 경우로 정의하였다 ${ }^{5}$. 원내 출생 극소 저체중출생아의 생후 초기 심장초음파는 신생아 전 임의, 신생아 의사 또는 소아심장과 의사에 의해 대략 다음과 같은 프로토콜로 시행되었다. 출생 직후부터 침습적 인공환기 치료가 필 요하거나, 혈 역학적 불안정성이 있는 경우 동맥관개존, 폐동맥고혈 압 및 심기능 이상을 확인하기 위하여 출생 24시간 이내 선별 심장 초음파가 시행되었고 담당 의사의 판단에 따라 필요한 경우 출생 1 주 이내에 추적검사를 시행하였다. 동맥관개존증에 대한 약물 치료 및 폐동맥고혈압에 대한 iNO 흡입 치료의 적응증이 되는 경우는 치 료 시작 시점과 치료 종료 후 심장초음파가 시행되었으며, 필요에 따라 추가로 검사가 시행되었다.

$\mathrm{iNO}$ 치료 시작과 종료는 임상의의 판단에 따라 아래와 같은 원내 
프로토콜에 따라 시행되었다. 치료 시작 용량은 5-10 ppm, 유지 용 량은 10-20 ppm이었고 최대 용량은 $40 \mathrm{ppm}$ 이었다. 환아가 임상적 으로 산소화의 호전을 보이고 $\mathrm{FiO}_{2}<50 \%$ 또는 OI < 10 인 경우 $\mathrm{iNO}$ 를 단계적으로 감량하였으며 적어도 $1 \mathrm{ppm}$ 에서 6시간 이상 유지된 경우 $\mathrm{iNO}$ 치료를 종료하였다.

연구 대상의 주산기 병력과 인구학적 특성, 치료 경과, 사망, 주 요 미숙아 합병증 등 임상 경과 관련 자료를 확인하였다. 주요 미숙 아 합병증으로 괴사성 장염(necrotizing enterocolitis) (Bell's criteria $\geq 2)^{18)}$, 중증 뇌실내출혈(intraventricular hemorrhage $\left.\geq 3\right)^{19)}$, 뇌실 주위백질연화증(periventricular leukomalacia) $)^{20)}$, 수술적 치료가 필 요한 미숙아 망막증(retinopathy of prematurity, $\mathrm{ROP})^{21)}$, 중등증 이 상의 $\mathrm{BPD}^{22}$ 등을 포함시켰다. 연구 대상군은 $\mathrm{iNO}$ 투여 후 1 시간째 의 치료 반응을 기준으로, 즉, 적용 1 시간째 $\mathrm{FiO}_{2}$ 또는 OI가 기저치 보다 $20 \%$ 이상 감소하는 경우를 반응군(responders)으로, $\mathrm{FiO}_{2}$ 와 OI 모두 위의 두 가지 기준을 충족하지 못한 경우 비반응군(nonresponders)으로 구분하였다 ${ }^{23)}$. 두 군의 주산기 및 미숙아 합병증 등 임상 경과 관련 자료를 분석하였다. 또한, $\mathrm{iNO}$ 사용 시작 시점 (0 hour) 및 iNO 치료 후 1시간, 6시간, 12시간, 24시간, 48시간, 72 시간, 96시간째 산소화 관련 지표인 OI와 산소포화도 지수(oxygen saturation index, OSI), 그리고 vasoactive-inotropic score (VIS)를 조사하였다. $\mathrm{OI}$ 는 $\mathrm{MAP} \times \mathrm{FiO}_{2} \times 100 / \mathrm{PaO}_{2}$ 로 $\mathrm{OSI}$ 는 $\mathrm{MAP} \times \mathrm{FiO}_{2} \times 100 /$ $\mathrm{SpO}_{2}$ 로, VIS는 dopamine $(\mathrm{\mu g} / \mathrm{kg} / \mathrm{min})+$ dobutamine $(\mu \mathrm{g} / \mathrm{kg} / \mathrm{min})+$ 100 $\times$ epinephrine $(\mathrm{\mu g} / \mathrm{kg} / \mathrm{min})+100 \times$ norepinephrine $(\mathrm{\mu g} / \mathrm{kg} / \mathrm{min})+$ 10×milrinone $(\mu \mathrm{g} / \mathrm{kg} / \mathrm{min})+10,000 \times$ vasopressin (units $/ \mathrm{kg} / \mathrm{min}$ )으 로 각각 정의하였다.

모든 통계분석은 SAS version 9.4 (SAS Institute, Cary, NC, USA) 를 사용하여 진행하였다. 임상 경과 관련 자료 중 범주형 변수들은 Fisher 정확검정으로 분석하였고, 연속형 변수들은 Mann-Whitney 검정으로 분석하였다. 연속측정 변수지표인 OI, OSI, VIS는 로그-

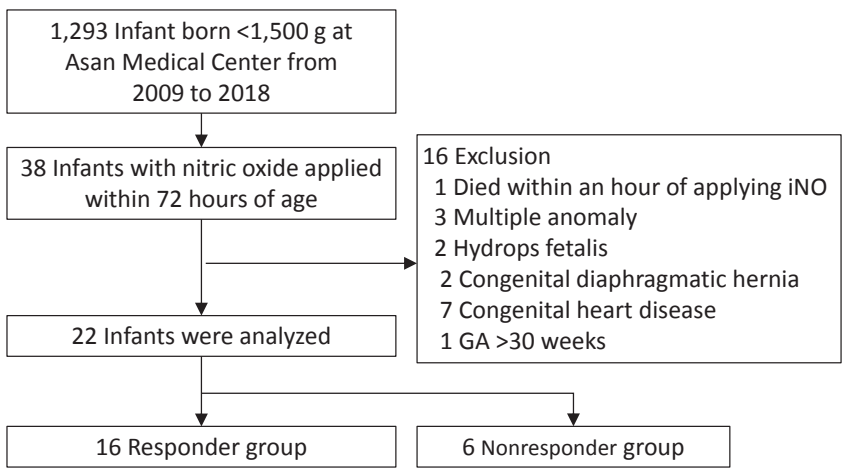

Figure 1. Flow chart of the study population. A total of 22 preterm infants were included in the analysis. Sixteen infants $(72 \%)$ are classified as responders to inhaled nitric oxide, and six infants (28 $\%)$ as nonresponders. Abbreviations: iNO, inhaled nitric oxide; GA, gestational age. 정규분포(log-normal distribution)를 가정한 Generalized Linear Mixed Model (GLMN)을 이용하여 분석한 후 절편의 변량효과(random effect)를 고려하였다. 각 시점별로 OI, OSI 간의 Spearman cor relation coefficient와 이에 대한 $P$ 값을 제시하였다. 모든 통계검정 에서 $P$ 값이 0.05 미만인 경우를 통계학적으로 유의하다고 판단하 였다.

결과

연구 기간 중 본원에서 출생한 극소 저체중출생아는 총 1,293 명이 었다. $\mathrm{iNO}$ 치료를 받은 총 94 명(7.2\%) 중 출생 72 시간 이내 적용한 환아는 38명이었고 이 중 다발성 선천기형이 확인된 3명, 태아수종

Table 1. Patient Characteristics (Responders vs. Nonrespon ders)

\begin{tabular}{|c|c|c|c|}
\hline Characteristic & $\begin{array}{l}\text { Response } \\
\text { group } \\
(n=16)\end{array}$ & $\begin{array}{c}\text { Nonresponse } \\
\text { group } \\
(n=6)\end{array}$ & $P$-value \\
\hline Male sex & $8(50.0)$ & $1(16.7)$ & 0.333 \\
\hline Gestational age (wk) & $260 / 7 \pm 20 / 7$ & $264 / 7 \pm 16 / 7$ & 0.796 \\
\hline Birth weight (g) & $872.6 \pm 281.3$ & $761.7 \pm 354.9$ & 0.531 \\
\hline Multiplicity & $2(12.5)$ & $3(50.0)$ & 0.100 \\
\hline Cesarean section & $12(75.0)$ & $2(33.3)$ & 0.137 \\
\hline SGA & $2(12.5)$ & $2(33.3)$ & 0.292 \\
\hline $\mathrm{PIH}$ & $2(12.5)$ & $2(33.3)$ & 0.292 \\
\hline Antenatal steroid & $16(100)$ & $6(100)$ & \\
\hline Apgar score at $1-\mathrm{min}$ & $3(2-4.5)$ & $3(1-5)$ & 1.000 \\
\hline Apgar score at 5-min & $6(4.5-6.5)$ & $5.5(5-6)$ & 0.970 \\
\hline Oligohydramnios & $10(62.5)$ & $3(50.0)$ & 0.655 \\
\hline PPROM & $10(62.5)$ & $1(16.7)$ & 0.149 \\
\hline PPROM (hr) & $381.0 \pm 617.5$ & $218.8 \pm 482.7$ & 0.353 \\
\hline Histologic chorioamnionitis & $8(50.0)$ & $4(66.7)$ & 0.646 \\
\hline Lung hypoplasia & $4(25.0)$ & $1(16.7)$ & 1.000 \\
\hline RDS & $16(100)$ & $6(100)$ & \\
\hline RDS, 2nd dose & $11(68.8)$ & $5(83.3)$ & 0.634 \\
\hline Postnatal age at iNO start (hr) & $12.1 \pm 14.5$ & $19.8 \pm 17.9$ & 0.103 \\
\hline Duration of iNO (d) & $8.6 \pm 9.4$ & $6.7 \pm 5.1$ & 0.760 \\
\hline OI at iNO start & $76.1 \pm 67.1$ & $31.1 \pm 18.8$ & 0.043 \\
\hline OSI at iNO start & $29.3 \pm 20.9$ & $11.7 \pm 4.5$ & 0.020 \\
\hline VIS at iNO start & $15.0 \pm 29.6$ & $6.3 \pm 7.3$ & 0.761 \\
\hline
\end{tabular}

Values are expressed as number (\%), mean \pm standard deviation, or median (interquartile range).

Abbreviations: SGA, small for gestational age; PIH, pregnancy induced hypertension; PPROM, preterm premature rupture of membrane; RDS, respiratory distress syndrome; iNO, inhaled nitric oxide; OI, oxygenation index; OSI, oxygen saturation index; VIS, vasoactiveinotropic score. 
2 명, 선천성 횡격막 탈장 2 명, 선천성 심장질환 7명(난원공, 2 차성 심방중격결손, 심실중격결손 제외), 재태주령 30주 이상 1 명, iNO 치료 한 시간 이내 사망 1 명을 제외한 후 총 22 명이 연구 분석에 포 함되었다(Figure 1).

연구 대상군에 포함된 환아의 평균 재태주령은 26주 1 일 $( \pm 2$ 주 0 일), 출생체중은 $842.3 \pm 298.4 \mathrm{~g}$ 이었다. 남아 비율은 $40 \%$, 쌍태아 의 비율은 $22 \%$ 였다. 4 명의 자궁내 성장지연아가 포함되었고 산전 스테로이드와 폐표면활성제는 전체 연구 환자군에서 투여되었다. 연구 대상 환자의 iNO 투약 전 평균 OI, OSI, VIS 값은 $63.8 \pm 61.0$, $18.3 \pm 10.6,12.6 \pm 25.6$ 였다.

환자군은 치료 시작 후 1 시간째 iNO에 대한 반응을 기준으로 반 응군(n=16,72.7\%)과 비반응군 $(n=6,27.3 \%)$ 으로 구분하였다. 두 군 간 재태주령, 출생체중, 조기양막파열 유무 및 조기양막파열 시간, 조직학적 융모막염, 양수감소증 등 주산기 임상 지표의 차이는 없 었다. 다만 $\mathrm{iNO}$ 치료 전 OI, OSI 값이 유의하게 반응군에서 높았다 (Table 1). Mixed effect model 분석에 따라 조사된 지표들의 반응군 과 비반응군 간의 차이와 시간에 따른 변화를 확인하였다. 반응군 과 비반응군 모두 $\mathrm{iNO}$ 투여 시작 후 시간이 경과하면서 산소화 지 표인 OI, OSI, $\mathrm{FiO}_{2}$ 의 유의한 변화가 확인되었다. 이들 산소화 지표
의 개선은 $\mathrm{iNO}$ 투여 1 시간 째부터 확인되었으며 기저치로부터의 변 화 폭은 반응군에서 더 현저하였다. 다만 기저치를 제외하고 $\mathrm{iNO}$ 투 여 1시간부터 96시간까지 반응군과 비반응군의 산소화 지표의 차이 는 없었다. VIS는 iNO 투여 후 치료 시작 후 24시간까지 증가한 이 후 감소하는 경향을 보였으며 두 군 간의 차이는 관찰되지 않았다 (Figure 2).

전체 환자들의 출생 1 년까지의 생존율은 $40.9 \%$ (9/22)였고, 사망 일의 중앙값은 출생 30일(24-141)이었다. 반응군과 비반응군의 1년 생존율은 각각 $43.8 \%$ 와 $33.3 \%$ 로 차이가 없었다(Figure 3). 반응군 과 비반응군의 생후 7 일(6.2\% vs. $16.6 \%), 28$ 일(25.0\% vs. $33.3 \%)$, 월경 후 연령 36 주(31.2\% vs. 33.3\%)에 확인한 단기 사망률도 차이 가 없었다. 두 군 간 주요 미숙아 합병증의 발생률도 차이는 없었다 (Table 2). OI와 OSI 값은 모든 측정 시점에서 유의한 양의 상관 관계 를 나타냈다(Table 3).

\section{고찰}

본 연구에서 중증 조기 폐동맥고혈압으로 진단된 극소 저체중출
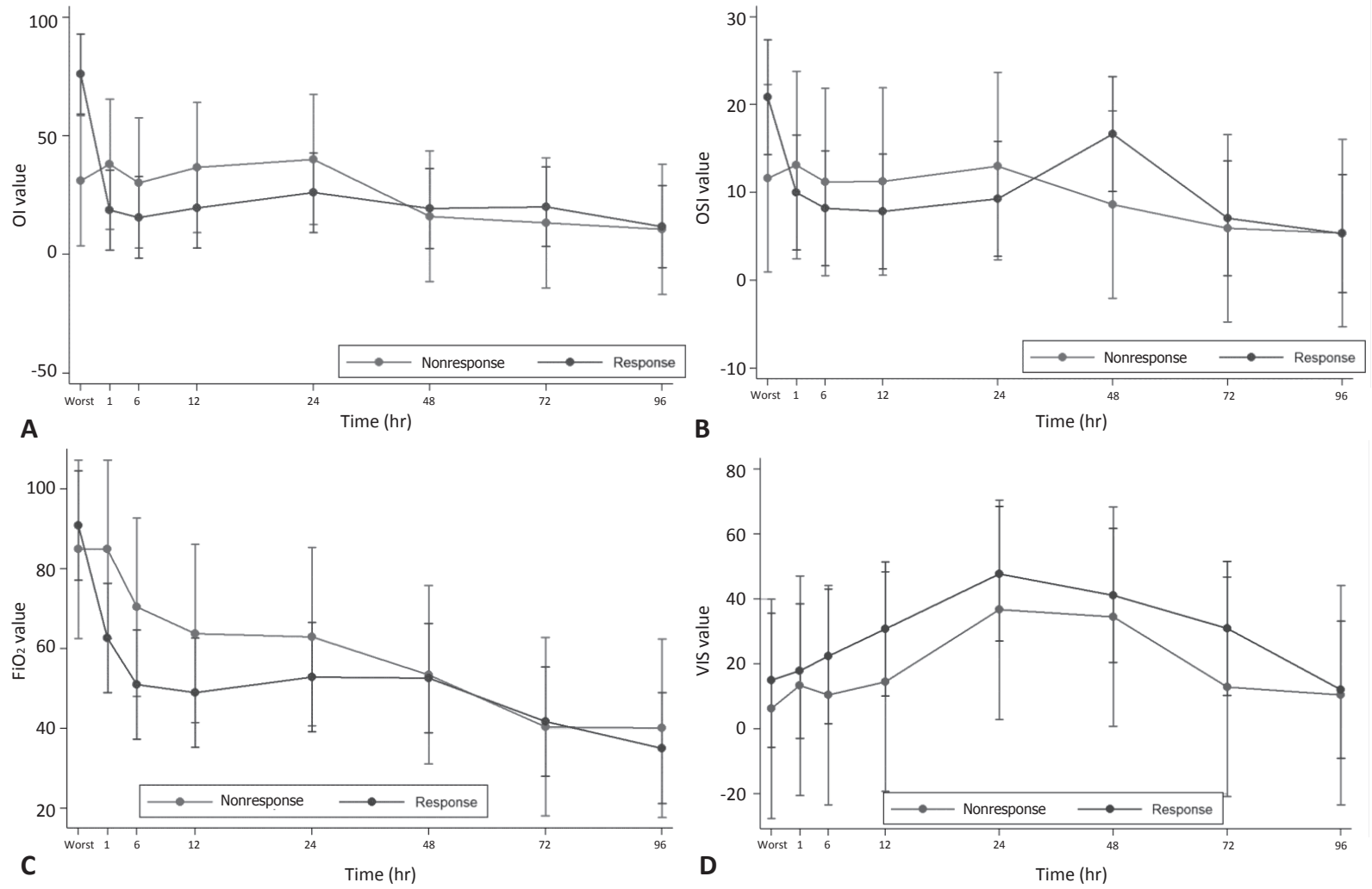

Figure 2. Comparison of treatment response to inhaled nitric oxide between the responders and nonresponders. (A) Oxygenation index (OI), (B) oxygen saturation index (OSI), (C) fraction of inspired oxygen $\left(\mathrm{FiO}_{2}\right)$, (D) vasoactive-inotropic score (VIS). Each vertical line represents confidence interval and each dot on the line represents predicted value. 


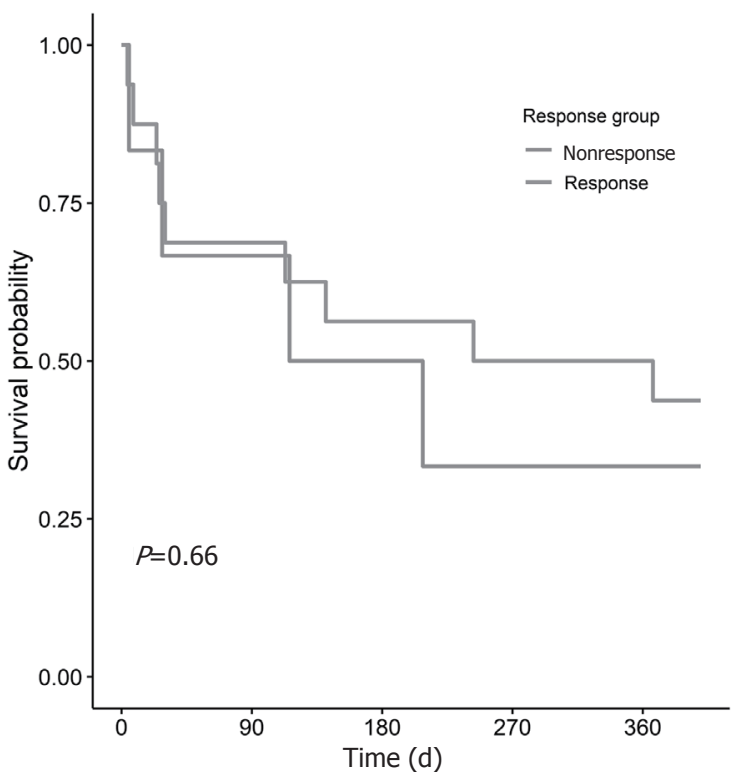

Figure 3. Kaplan-Meier survival estimates of infants in the responders and nonresponders.

Table 2. Clinical Outcomes (Responders vs. Nonresponders)

\begin{tabular}{lccc}
\hline Variable & $\begin{array}{c}\text { Response } \\
\text { group } \\
(\mathrm{n}=16)\end{array}$ & $\begin{array}{c}\text { Nonresponse } \\
\text { group } \\
(\mathrm{n}=6)\end{array}$ & $P$-value \\
\hline Mortality & $9(56.2)$ & $4(66.7)$ & 1.000 \\
PDA treatment & $8(50.0)$ & $1(16.7)$ & 0.333 \\
NEC stage $\geq 2$ & $1(6.2)$ & 0 & 1.000 \\
IVH grade $\geq 3$ & $6(37.5)$ & $4(66.7)$ & 0.348 \\
PVL & $3(18.8)$ & $1(16.7)$ & 1.000 \\
SIP & 0 & $1(16.7)$ & 0.273 \\
ROP treatment & $3(27.3)$ & $1(25.0)$ & 1.000 \\
Early-onset sepsis & $1(6.2)$ & $0(0)$ & 1.000 \\
Late-onset sepsis & $11(73.3)$ & $2(33.3)$ & 0.146 \\
Survival at PMA 36 wk & 11 & 4 & 1.000 \\
Moderate/severe BPD & $9(81.8)$ & $3(75)$ & 1.000 \\
Severe BPD & $9(81.8)$ & $3(75)$ & 1.000 \\
BPD steroid & $10(90.9)$ & $2(50.0)$ & 0.154 \\
Duration of hospitalization (d) & $133.6 \pm 116.5$ & $94.5 \pm 78.9$ & 0.747 \\
Duration of invasive MV (d) & $88.3 \pm 87.3$ & $64.7 \pm 67.1$ & 0.606 \\
Late PH & $5(45.5)$ & $3(75.0)$ & 0.569 \\
\hline V & &
\end{tabular}

Values are expressed as number (\%) or mean \pm standard deviation. Abbreviations: PDA, patent ductus arteriosus; NEC, necrotizing enterocolitis; IVH, intraventricular hemorrhage; PVL, periventricular leukomalacia; SIP, spontaneous intestinal perforation; ROP, retinopathy of prematurity; PMA, postmenstrual age; BPD, bronchopulmonary dysplasia; MV, mechanical ventilator; $\mathrm{PH}$, pulmonary hypertension.
Table 3. Correlation Coefficient Summarizing Relationship between Oxygenation Index and Oxygen Saturation Index in Responders and Nonresponders

\begin{tabular}{lcc}
\hline Time (hr) & Correlation coefficient & $P$-value \\
\hline 0 & 0.84 & $<0.001$ \\
1 & 0.73 & $<0.001$ \\
6 & 0.93 & $<0.001$ \\
12 & 0.99 & $<0.001$ \\
24 & 0.98 & $<0.001$ \\
48 & 0.97 & $<0.001$ \\
72 & 0.93 & $<0.001$ \\
96 & 0.86 & $<0.001$
\end{tabular}

생아의 1 년 생존율은 $40.9 \%$ 로 최근 보고된 국내 극소 저체중출생아 의 단기 생존율인 $86.4 \%$ 에 비해 현저히 낮았다 ${ }^{24}$. 본 연구의 사망률 은 미숙아의 호흡부전이 동반된 초기 폐동맥고혈압 환자를 대상으 로 확인된 선행 연구의 결과와 유사하다. Dani 등이는 30 주 미만 또 는 $1,250 \mathrm{~g}$ 미만 환자 중 저산소성 호흡부전이 있는 42 명 중 PPHN 이 있는 경우는 $43 \%, \mathrm{PPHN}$ 이 없는 경우는 $57 \%$ 의 사망률을 보고하 였다. Rallis 등 ${ }^{17)}$ 의 보고에 따르면 34주 미만 미숙아에서 생후 72시 간 이내 진단된 조기 폐동맥고혈압 환아 55 명의 사망률은 $39 \%$ 였다. Baczynski 등 23 의 연구에서는 35 주 미만 조기 폐동맥고혈압 환아 89 명의 사망률이 $53 \%$ 로 나타났다.

앞서 언급된 논문에서는 $\mathrm{iNO}$ 치료 효과를 반응군과 비반응군으 로 구분하여 확인하였는데 치료 효과 판정 시점이 iNO 투여 시작 후 1시간 ${ }^{23}$ 또는 3 시간 ${ }^{917)}$ 을 기준으로 하여 일관되지는 않았으나, $\mathrm{FiO}_{2} 20 \%$ 이상의 감소가 나타나는 반응군에서 높은 생존율이 보고 된바 있다 ${ }^{9,17,23)}$. 본 연구에서는 iNO 치료 반응군 정의에 대하여 앞 서 언급한 연구들과 유사한 판정 기준을 적용하였음에도 불구하고 비반응군 대비 반응군의 생존율 향상이 확인되지 않았다. 이는 단 순히 환자 표본수가 상대적으로 적은 것에 기인한 결과일 수 있겠 으나 여러 다른 요인들을 감안해야 한다. 본 연구의 대상은 재태주 령 30주 미만의 극소 저출생체중아로서 앞선 연구들에 비하여 상대 적으로 미숙하고 출생체중이 작아 비록 $\mathrm{iNO}$ 반응군이라도 상대적 으로 사망률과 합병증의 비율이 높을 수 있다. 또한, 반응군과 비반 응군을 구분하는 $\mathrm{iNO}$ 투여 후 시점의 차이가 1 시간째로 비교적 빠 른 편이었으며 $\mathrm{FiO}_{2}>20 \%$ 이상 감소라는 기준과 병행하여 OI의 기 준을 적용한 점에서 차이가 있다. $\mathrm{FiO}_{2}$ 의 경우 동맥혈검사상의 산소 농도가 반영된 OI 값에 비하여 상대적으로 치료자의 판단에 따라 결 정되는 경향이 있다. 이번 연구에서 OI의 변화가 치료 후 1 시간과 6 시간 사이의 변동이 관찰되지 않는 반면 $\mathrm{FiO}_{2}$ 는 1시간에서 6시간으 로 갈수록 낮아지는 경향이 관찰되었다. 따라서 일반적으로 신생아 에서 $\mathrm{iNO}$ 의 효과는 치료 즉시 확인되는 것을 감안한다면 ${ }^{25)}$, iNO에 대한 반응군은 보다 빠른 시점에서 $\mathrm{FiO}_{2}$ 보다 상대적으로 객관적인 
OI를 기준으로 결정하는 것이 더 합리적일 수 있다. 참고로 이번 연 구에서 생후 6시간째의 iNO의 반응을 기준으로 주요 결과를 확인 해 보면 비록 통계적으로 유의하지는 않으나 반응군의 사망률 $(9 / 18$, $50 \%)$ 이 비반응군의 사망률( $4 / 4,100 \%)$ 보다 높은 경향을 보인다. 그 렇지만 6 시간째의 반응이 1 시간째의 반응보다 향후 예후를 더 잘 예 측할 수 있는지에 대한 분석은 본 자료만으로는 한계가 있었다.

본 연구는 생후 3 일 이내 확인된 초기 중증 폐동맥고혈압이 있는 초극소 저출생체중아의 약 $70 \%$ 이상에서 $\mathrm{iNO}$ 의 신속한 산소화 개 선 반응을 확인할 수 있었다. 이는 장시간의 조기양막파열에 합병 등 여러 가지 요인에 합병된 미숙아에서 발생한 생후 초기 폐동맥고 혈압에서 확인된 기존의 iNO 효과를 재확인한 것이다,12,17,23,26). 태 아기 양을 대상으로 한 동물 실험에서 동맥혈 산소농도에 대한 폐혈 관저항의 감소 반응은 재태주령이 증가할수록 현저하였으며, 이를 감안할 때 미숙아에서 발생한 폐동맥고혈압은 만삭아의 상황에 비 하여 산소 치료에 대한 효과가 낮을 것으로 예상된다 ${ }^{15}$. 조기양막파 열, 양수감소증, 폐형성저하, 자궁내 성장지연 등의 원인을 가지고 있는 환아들에서 $\mathrm{iNO}$ 치료의 효과가 좋은 것으로 알려져 있는데 ${ }^{27}$ 이는 proinflammatory cytokines 감소 및 일산화질소 결핍이라는 공 통의 병태생리기전을 가지고 있기 때문으로 생각된다. 미숙아들은 $\mathrm{FiO}_{2} 50 \%$ 이상의 산소분압에 대한 폐혈관저항의 감소 효과가 크지 않고, 오히려 동맥혈 산소분압의 증가가 iNO의 효과를 떨어뜨릴 가 능성도 제시되고 있다 ${ }^{28}$. 따라서 만삭아와 달리 조기 폐동맥고혈압 이 확인된 미숙아에서는 목표 산소 농도에 도달하기 위한 보존적 치 료의 반응이 없을 경우 $\mathrm{BPD}$, 백질손상 및 ROP의 위험을 높일 수 있 는 고농도 산소 투여의 효과를 기다린 후 이에 반응이 없는 경우 구 제 치료로서 $\mathrm{iNO}$ 를 사용하는 것보다는 가능한 초기에 $\mathrm{iNO}$ 치료를 시도해 보는 것이 더 효과적일 가능성이 있다.

OI-OSI 값의 상관성은 모든 측정 시점에서 통계적으로 유의하였 다. 폐동맥고혈압이 동반된 환자에서 $\mathrm{OI}>15$ 일 때 $\mathrm{iNO}$ 를 적용하는 치료방침을 적용하고, 치료에 대한 반응 또한 OI로 해석하고 있지 만, 침습적인 동맥혈 가스분석을 시행하여야 하는 단점이 있다. 이 를 대체하는 방법으로 OI와 OSI의 관계를 심한 저산소성 호흡부전 이 있는 환아에게 비교 분석하여 비침습적인 OSI로 치료반응을 평 가하고자 하는 선행연구들이 있었지만 ${ }^{29,30}$ 폐동맥고혈압 특히 미숙 아의 폐동맥고혈압에서 적용한 연구는 없었다. 산소해리곡선에 헤 모글로빈의 종류, 수소이온농도, 온도 등이 영향을 줄 수 있고, 또한 너무 낮거나 높은 $\mathrm{PaO}_{2}$ 에서 $\mathrm{SpO}_{2}$ 와의 상관관계를 벗어남에도 불구 하고 비침습적인 OSI로 침습적인 동맥혈 가스분석을 통해서 얻어지 는 OI를 대신할 수 있음을 확인한 것은 의미 있었다.

미숙아에서 iNO의 사용에 대한 교과서적 지침은 없다. 최근 Pediatric Pulmonary Hypertension Network는 iNO는 만성 폐질환의 예 방을 위한 목적으로 사용되어서는 안되지만 폐실질병변이 아닌 지 속성 폐동맥고혈압의 병태 생리로 인한 심한 저산소증이 있는 미숙
아에서 $\mathrm{iNO}$ 사용의 이점을 제시한바 있다 ${ }^{10)}$. 그럼에도 불구하고 해 당 환자군에서 여전히 iNO의 사용에 대한 우려와 제약이 현실적으 로 존재한다. 조기 중증 폐동맥고혈압이 있는 미숙아에서 $\mathrm{iNO}$ 사용 의 효과에 대한 전향적 무작위 대조 연구는 없으며 다양한 증례 보 고를 통해 정리된 권장사항이 있을 뿐이다. 공인된 $\mathrm{iNO}$ 치료제인 iNOMAX의 전 세계적인 보험 기준 역시 대부분 재태주령 34 주 이상 으로 지정되어 있고 한국의 보험 적용기준 또한 동일하여 34 주 미만 의 환아에게서 $\mathrm{iNO}$ 사용은 제한적 일수밖에 없다.

본 연구에서는 몇 가지 제한점이 있다. 첫째, 본 연구는 후향적 연 구로서 $\mathrm{iNO}$ 효과 판정을 위한 $\mathrm{OI}$ 값의 결과만 확인하였다. $\mathrm{SpO}_{2}$ 의 경우 오른 손목에서 결과를 확인하였지만, $\mathrm{PaO}_{2}$ 의 경우 제대도관 에서 얻어진 결과인지 말초 A-line에서 얻어진 결과인지를 구분하 지 못하였다. 둘째, 대상 환자수가 적어 iNO 조기 치료의 효과를 확 인할 수 없었을 가능성이 있다. 셋째, 조기 사망환자가 많아 ROP 및 만성 폐질환 등 주요 미숙아 합병증에 대한 영향이 왜곡되었을 가능 성이 있다.

결론적으로, 본 연구를 통해 출생 초기 중증 폐동맥고혈압이 있는 극소 저체중출생아에서 $\mathrm{iNO}$ 치료가 산소화 개선에 신속한 효과를 나타내는 것을 확인할 수 있었다. 다만 iNO에 대한 반응 여부로는 사망 및 미숙아 합병증을 예측할 수 없었다. 생후 초기 중증 폐동맥 고혈압이 있는 미숙아에서 $\mathrm{iNO}$ 의 선제적 사용이 향후 생존율을 향 상시킬 수 있는지에 대한 대규모 연구가 필요하다.

\section{ARTICLE INFORMATION}

\section{Ethical statement}

The study protocol was reviewed and approved by the Institutional Review Board of Asan Medical center (identification code: 2019-0268) in accordance with the Declaration of Helsinki. The Institutional Review Board waived the need for informed consent for this retrospective chart review.

\section{Conflicts of interest}

No potential conflict of interest relevant to this article was reported.

\section{Author contributions}

Conception or design: B.S.L., E.J., A.R.K., K.S.K.

Acquisition, analysis, or interpretation of data: J.Y.C., M.Y.O., T.C., J.J.

Drafting the work or revising: J.Y.C., B.S.L.

Final approval of the manuscript: B.S.L. 


\section{ORCID}

Jae Young Cho https://orcid.org/0000-0002-3654-067X

Byong Sop Lee https://orcid.org/0000-0002-1347-4200

\section{Acknowledgments}

None

\section{REFERENCES}

1. Lakshminrusimha S, Saugstad OD. The fetal circulation, patho physiology of hypoxemic respiratory failure and pulmonary hypertension in neonates, and the role of oxygen therapy. J Perinatol 2016;36 Suppl 2:S3-11.

2. Barrington KJ, Finer N, Pennaforte T, Altit G. Nitric oxide for respiratory failure in infants born at or near term. Cochrane Database Syst Rev 2017;1:CD000399.

3. Lakshminrusimha S, Keszler M. Persistent pulmonary hypertension of the newborn. Neoreviews 2015;16:e680-92.

4. Kumar VH, Hutchison AA, Lakshminrusimha S, Morin FC 3rd, Wynn RJ, Ryan RM. Characteristics of pulmonary hypertension in preterm neonates. J Perinatol 2007;27:214-9.

5. Nakanishi H, Suenaga H, Uchiyama A, Kusuda S; Neonatal Research Network, Japan. Persistent pulmonary hypertension of the newborn in extremely preterm infants: a Japanese cohort study. Arch Dis Child Fetal Neonatal Ed 2018;103:F554-61.

6. Chambers CD, Hernandez-Diaz S, Van Marter LJ, Werler MM, Louik C, Jones KL, et al. Selective serotonin-reuptake inhibitors and risk of persistent pulmonary hypertension of the newborn. N Engl J Med 2006;354:579-87.

7. Katz N, Bar-Or Y, Raucher-Sterrnfeld A, Tamir A, Kohelet D. Persistent pulmonary hypertension and histologic chorioam nionitis in preterm infants: controlled study. Pediatr Cardiol 2018;39:705-8.

8. Gijtenbeek M, Haak MC, Ten Harkel DJ, Te Pas AB, Middeldorp JM, Klumper FJCM, et al. Persistent pulmonary hypertension of the newborn in twin-twin transfusion syndrome: a case-control study. Neonatology 2017;112:402-8.

9. Dani C, Corsini I, Cangemi J, Vangi V, Pratesi S. Nitric oxide for the treatment of preterm infants with severe RDS and pulmonary hypertension. Pediatr Pulmonol 2017;52:1461-8.

10. Kinsella JP, Steinhorn RH, Krishnan US, Feinstein JA, Adatia I, Austin ED, et al. Recommendations for the use of inhaled nitric oxide therapy in premature newborns with severe pulmonary hypertension. J Pediatr 2016;170:312-4.

11. Barrington KJ, Finer N, Pennaforte T. Inhaled nitric oxide for respiratory failure in preterm infants. Cochrane Database Syst Rev 2017;1:CD000509.
12. de Waal K, Kluckow M. Prolonged rupture of membranes and pulmonary hypoplasia in very preterm infants: pathophysiology and guided treatment. J Pediatr 2015;166:1113-20.

13. Park GY, Park WS, Yoo HS, Ahn SY, Sung SI, Kim SS, et al. Shortterm outcomes comparison between preterm infants with and without acute hypoxic respiratory failure attributable to presumed pulmonary hypoplasia after prolonged preterm premature rupture of membranes before 25 gestational weeks. J Matern Fetal Neonatal Med 2019;32:1938-45.

14. Ellsworth KR, Ellsworth MA, Weaver AL, Mara KC, Clark RH, Carey WA. Association of early inhaled nitric oxide with the survival of preterm neonates with pulmonary hypoplasia. JAMA Pediatr 2018;172:e180761.

15. Lewis AB, Heymann MA, Rudolph AM. Gestational changes in pulmonary vascular responses in fetal lambs in utero. Circ Res 1976;39:536-41.

16. Choi EJ, Sohn JA, Lee EH, Lee JY, Lee HJ, Choi CW, et al. The effect of inhaled nitric oxide in preterm infants less than $1,250 \mathrm{~g}$ with respiratory failure. Korean J Perinatol 2011;22:37-46.

17. Rallis D, Deierl A, Atreja G, Chaban B, Banerjee J. The efficacy of inhaled nitric oxide treatment in premature infants with acute pulmonary hypertension. Early Hum Dev 2018;127:1-5.

18. Bell MJ, Ternberg JL, Feigin RD, Keating JP, Marshall R, Barton L, et al. Neonatal necrotizing enterocolitis: therapeutic decisions based upon clinical staging. Ann Surg 1978;187:1-7.

19. Papile LA, Burstein J, Burstein R, Koffler H. Incidence and evolution of subependymal and intraventricular hemorrhage: a study of infants with birth weights less than 1,500 gm. J Pediatr 1978;92:529-34.

20. deVries LS, Eken P, DubowitzLM. The spectrum ofleukomalacia using cranial ultrasound. Behav Brain Res 1992;49:1-6.

21. International Committee for the Classification of Retinopathy of Prematurity. The international classification of retinopathy of prematurity revisited. Arch Ophthalmol 2005;123:991-9.

22. Ehrenkranz RA, Walsh MC, Vohr BR, Jobe AH, Wright LL, Fanaroff AA, et al. Validation of the National Institutes of Health consensus definition of bronchopulmonary dysplasia. Pediatrics 2005;116:1353-60.

23. Baczynski M, Ginty S, Weisz DE, McNamara PJ, Kelly E, Shah $P$, et al. Short-term and long-term outcomes of preterm neonates with acute severe pulmonary hypertension following rescue treatment with inhaled nitric oxide. Arch Dis Child Fetal Neonatal Ed 2017;102:F508-14.

24. Chung SH, Bae CW. Improvement in the survival rates of very low birth weight infants after the establishment of the Korean neonatal network: comparison between the 2000s and 2010s. J Korean Med Sci 2017;32:1228-34.

25. Day RW, Lynch JM, White KS, Ward RM. Acute response to inhaled nitric oxide in newborns with respiratory failure and pulmonary hypertension. Pediatrics 1996;98:698-705. 
26. Semberova J, O'Donnell SM, Franta J, Miletin J. Inhaled nitric oxide in preterm infants with prolonged preterm rupture of the membranes: a case series. J Perinatol 2015;35:304-6.

27. Aikio O, Metsola J, Vuolteenaho R, Perhomaa M, Hallman $\mathrm{M}$. Transient defect in nitric oxide generation after rupture of fetal membranes and responsiveness to inhaled nitric oxide in very preterm infants with hypoxic respiratory failure. J Pediatr 2012;161:397-403.
28. Steinhorn RH. Advances in neonatal pulmonary hypertension. Neonatology 2016;109:334-44.

29. Rawat M, Chandrasekharan PK, Williams A, Gugino S, Koenigsknecht C, Swartz D, et al. Oxygen saturation index and severity of hypoxic respiratory failure. Neonatology 2015;107:161-6.

30. Muniraman HK, Song AY, Ramanathan R, Fletcher KL, Kibe R, Ding $\mathrm{L}$, et al. Evaluation of oxygen saturation index compared with oxygenation index in neonates with hypoxemic respiratory failure. JAMA Netw Open 2019;2:e191179. 